\title{
A New Hybrid Artificial Neural Network Based Control of Doubly Fed Induction Generator
}

\author{
G. Venu Madhav*, Y. P. Obulesu** \\ * Department of Electrical and Electronics Engineering, B. V. Raju Institute of Technology, India \\ ** Department of Electrical and Electronics Engineering, KL University, India
}

\begin{tabular}{l}
\hline Article Info \\
\hline Article history: \\
Received Nov 14, 2014 \\
Revised Feb 19, 2015 \\
Accepted Mar 2, 2015 \\
\hline
\end{tabular}

\section{Keyword:}

Control strategy

Doubly fed induction generator

Neural networks

Proportional integral

Wind power generation

\begin{abstract}
In this paper, Hybrid Artificial Neural Network (ANN) with Proportional Integral (PI) control technique has been developed for Doubly Fed Induction Generator (DFIG) based wind energy generation system and the performance of the system is compared with NN and PI control techniques. With the increasing use of wind power generation, it is required to instigate the dynamic performance analysis of Doubly Fed Induction Generator under various operating conditions. In this paper, three control techniques have been proposed, the first one is using PI controller, the second one is ANN control, and the third one is based on combination of ANN and PI. The performance of the proposed control techniques is demonstrated through the results, determined by using MATLab/Simulink. From the results it is observed that the dynamic performance of the DFIG is improved with the Hybrid control technique.
\end{abstract}

Copyright (C) 2015 Institute of Advanced Engineering and Science. All rights reserved.

\section{Corresponding Author:}

G. Venu Madhav

Department of Electrical and Electronics Engineering,

Padmasri Dr. B. V. Raju Institute of Technology,

Vishnupur, Narsapur, Medak Dist., 502313,

AP, India.

Email: venumadhav.gopala@gmail.com

\section{INTRODUCTION}

Most of the countries in the world are now concentrating on renewable energy sources, in particularly wind energy. The increase in size and level of penetration of the wind farms has major impact on the power system including the unit commitment and load dispatch. It has impact on the voltage of the feeder and the substation when a local power system is considered, [1]-[2].

The increase in the growth and installed capacity of wind farms makes it necessary to investigate and develop different control capabilities and strategies. With the necessary control techniques, the wind farms can be made with the same features as that of conventional power plants. These capabilities and strategies includes the control of output active power and reactive power of the total wind farm, the control of affect of parameters of wind farm for any kind of abnormal condition in the grid. This makes the wind power plants to act as active components of the power supply system.

The purpose and the main aim of these control capabilities are to optimize the generated power and to manage the safe limits along with automatic operation of the wind turbine. The optimization of generated power reduces the operating costs, enables uniform dynamic response and better product quality, and helps to minimize turbine loads which make safe operation of wind turbine with maximizing the capture of wind energy.

With the aim of extracting the maximum wind power applied to fixed or variable speed wind turbines, many control strategies were developed by so many authors. 
The performances like stability analysis and turbine control to improve the power generated with the lowest impact on the grid voltage and frequency during normal operation and under several abnormal conditions, such as a transmission line earth fault are described in this paper, for wind generation models operated within the power system. The wind turbines based on Doubly Fed Induction Generator (DFIG) and a grid-connected converter with constant or variable blade angle applied to variable speed wind energy system is considered in this paper. The methodology is investigated and implemented by using the toolboxes and block sets of MATLab/Simulink [3].

The engineering and design of a Doubly Fed Induction Generator (DFIG) using AC/DC/AC PWM voltage source converters in the rotor circuit and vector control applied to both Grid Side Converter (GSC) and Rotor Side Converter (RSC) without considering any abnormal condition is described in [4]. [5] is restricted to the reactive power control of a wind farm with the implementation of PI control and proportional distribution, concluding that PI is more robust compared to proportional distribution. The vector control is applied to GSC [6], in this supervisory systems controls active and reactive power of the whole wind farm and a machine control system ensures that set points at the wind turbine level are reached. The analysis of stator flux oriented vector control theory of Doubly Fed Induction Generator (DFIG) was introduced in [7]. A Maximum Power Point Tracking (MPPT) and control strategy for the unity power factor of stator output is described. In [8], again the stator flux oriented frame is introduced for easy decomposition of active and reactive powers on the stator side along with introduction of linear PI control around the stator currents ensuring good stability provided the gains are suitably selected. A robust regulation of the primary side active and reactive power by the components of the stator currents is introduced in [9] and is synthesized by using PI controller. In all the mentioned literature the traditional method of vector control is used with PI controller and the performance is restricted to steady state and not analyzed for transient or grid fault conditions.

The control of rotor currents by voltage mode controller by using the vector control scheme [10], which allows for adjustable speed operation and reactive power control along with correcting the problems caused by unbalanced stator voltages. The reactive power generation of offshore wind parks using DFIGs is explained in [11] and it describes the steady state operation with minimum power loss of wind energy by new adaptive Particle Swarm Optimization (PSO) and also describes the condition of fault. The fault condition is avoided by the fault ride through capability by using crowbar protection, which blocks the RSC and the stator reactive current cannot be controlled. The control of reactive power independently of the active power flow using both RSC and GSC with application of linear control techniques and it is not analyzed for the grid fault condition [12].

Two different control strategies i.e., PI and Artificial Neural Network (ANN) and the operation of the DFIG is analyzed in [13], during the steady state and transient grid fault operation. The paper describes the replacement of traditional method of vector control by ANN, the ANN controllers' architecture used is of conventional type, which can be replaced by more sophisticated and highly accurate Graphical User Interfaces (GUIs) for better improvement in the performance. In [13], by using ANN, there are still some overshoots, faster response compared to PI controller and existence of oscillatory behavior during the transient or abnormal condition. This can be avoided by using the Hybrid controller and the performance of the DFIG can be much improved.

In this paper, three power control techniques are investigated and they are: Proportional Integral (PI) controller based technique; Artificial Neural Network (ANN) based technique and combination of ANN and PI control technique for better dynamic control of DFIG. In this work as mentioned, a new hybrid controller is introduced, which consists of both ANN and PI controllers that means both the advantages of ANN and PI controllers are embedded into one single controller. Compared to the performance of the ANN and PI controller, the hybrid controller system estimates the control parameters of the DFIG more prominently, which can be easily understood by the satisfactory performance characteristics of DFIG presented in results and discussion section and also during the transient condition the hybrid controller presents absence or smaller overshoots, the system makes to stable operation in lesser time, and smaller oscillatory behavior and this can be observed even during the fault condition. To ensure better stability and power regulation generated by the wind turbine the Hybrid technique will allow the increase of robustness, performance, and flexibility.

\section{MODELING OF DFIG}

In this research work, the overall control structure of the model that is used includes aerodynamic, mechanical and electric system components, with an overall system of control model. The electric model and the aerodynamic model interface with the grid model and the wind model respectively, [1]-[2].

IJECE Vol. 5, No. 3, June 2015 : $379-390$ 


\subsection{Doubly Fed Induction Generator}

The DFIG model adopted in this research paper is the qd0 stationary rotating reference frame. It is because the model simulation of Doubly Fed Induction Machine (DFIM) is quite suitable with this frame of reference during transients. The transient solution of the DFIM model is possible because of the transformation from $\mathrm{abc}$ to $\mathrm{qd} 0$ by which the differential equations with time-varying inductances is converted into differential equations with constant inductances, [5]-[6].

$$
\begin{aligned}
& v_{q s}=R_{s} i_{q s}+\omega \Psi_{d s}+\frac{d \Psi_{q s}}{d t} \\
& v_{d s}=R_{s} i_{d s}-\omega \Psi_{q s}+\frac{d \Psi_{d s}}{d t} \\
& v_{q r}^{\prime}=R_{r}^{\prime} i_{q r}^{\prime}+\left(\omega-\omega_{r}\right) \Psi_{d r}^{\prime}+\frac{d \Psi_{q r}^{\prime}}{d t} \\
& v_{d r}^{\prime}=R_{r}^{\prime} i_{d r}^{\prime}-\left(\omega-\omega_{r}\right) \Psi_{q r}^{\prime}+\frac{d \Psi_{d r}^{\prime}}{d t} \\
& T_{e m} \approx \frac{3}{2} \frac{p}{2} L_{m}\left(i_{d r}^{\prime} i_{q s}-i_{q r}^{\prime} i_{d s}\right)
\end{aligned}
$$

In this paper, the performance and the stability of the DFIG system is verified for transient condition state when active and reactive powers are varied respectively and also verified when a phase to earth fault is occurred, when DFIG is continuously connected to the grid system and is continuously fed with mechanical input torque.

\subsection{AC/DC/AC Converter}

By using the AC/DC/AC converter, bidirectional power flow can be achieved from the grid to the DFIM and from the DFIM to the grid that means from the rotor of the DFIM, the current can be injected or received with the current flowing in both the directions [5]. Nominally 30 to $40 \%$ of the generated power is fed back to the grid through the PWM back-to-back converter and also by employing the back-to-back converter the fluctuations in voltage, frequency, and wind turbine output power can be easily controlled. The output power of DFIG, which has fluctuating non-grid frequency can be controlled by PWM converter to a $\mathrm{DC}$ Voltage level and it will be injected through $\mathrm{AC} / \mathrm{DC} / \mathrm{AC}$ converter into three-phase grid frequency power, [4].

This PWM back-to-back converter has a combination of two converters, one is called as Grid Side Converter (GSC) and the other one is called as Rotor Side Converter (RSC), as Figure 1. The main objective of the GSC is to keep the DC voltage of the DC-link capacitor to be constant, independent of the direction of the power flow of rotor, in order to guarantee the exchange of reactive power only through the stator as by maintaining the power factor to be equal to unity.

Likewise, the main objective of the RSC is to achieve indirect control of active and reactive power independently by control over the rotor current, [4].

\section{PI CONTROLLER BASED DFIG}

In order to optimize the operation of the wind turbine likewise number of wind turbines in a wind park, it is necessary to control the active and reactive power flows with a consideration that the wind turbine will generate maximum output power to the grid. Thus, an adequate control should have [4]:

1. Achievable optimized operating point by control of active power supplied by the wind turbine;

2. Restricted generation of active power when wind speed is very high;

3. Controlled interchange of reactive power between the generator and the grid where in general the fluctuation in voltage occurs especially in weak grids;

4. Constant grid voltage in case of a wind park or wind turbine;

5. Minimized costs of maintenance and the exploration in case of wind park or wind turbine.

Several control strategies were proposed in order to achieve the points mentioned above. The vector control strategy is applied to DFIG in order to achieve the independent control of active and reactive power [4]-[5], by decoupling the rotor current into quadrature ' $q$ ' and direct' $d$ ' axis components. In this paper, the 
vector control strategy is described with PI controller, ANN control and Hybrid combination i.e., ANN+PI control and results are compared.

A typical configuration of proposed Hybrid ANN with PI control based DFIG is illustrated in Figure 1. In place of Hybrid ANN with PI control, an individual configuration of Neural Networks (NN) and PI controllers are employed and the obtained simulation results for these configurations are compared and tabulated.

As shown in Figure 1, the optimal reference value of active power is given by Pref, which in general obtained from the characteristics of the wind turbine and the optimal value of reactive power Qref is chosen such that at the grid connection point the voltage is maintained stable.

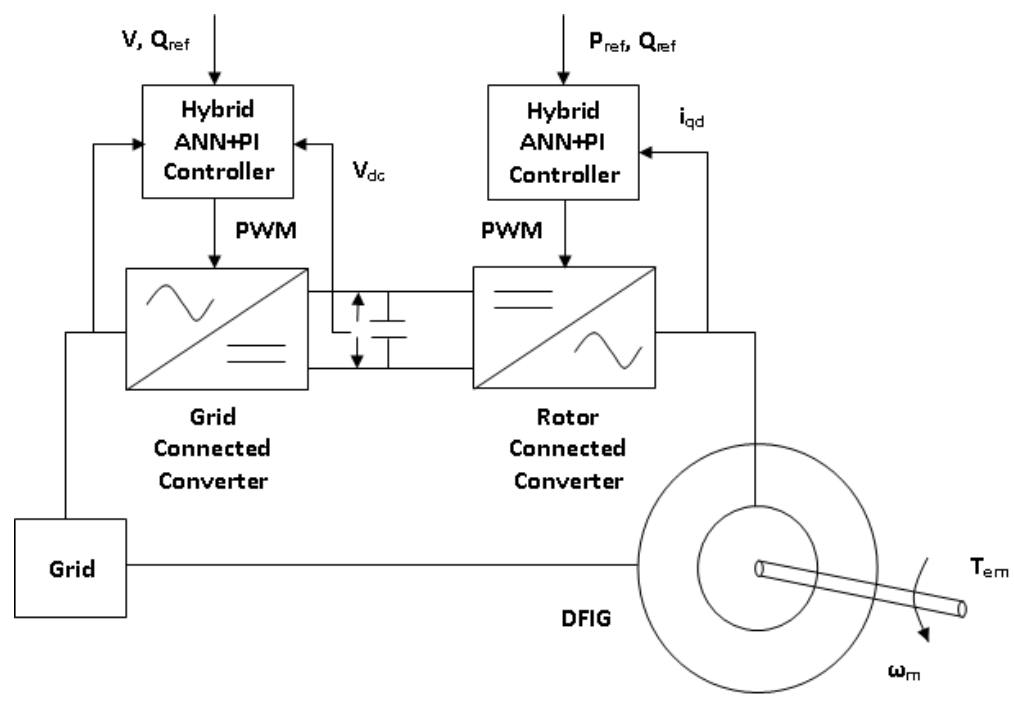

Figure 1. Proposed control strategy

\subsection{Grid-Side Converter Control}

The vector control strategy is applied to the GSC to achieve the independent control of active and reactive power between the converter and the grid. The strategy is used with respect to the position of the stator or grid reference voltage axis. The typical configuration of GSC control strategy is shown in Figure 2.

As shown in Figure 2, the PI controllers are adopted for the internal control loop obtained by the Laplace transform of (6) and (7) that represents the GSC voltages in its dq components, [4]. In this research work, the generalized PI controllers are replaced by normalized controllers like ANN and Hybrid controllers and the performances are observed.

$$
\begin{aligned}
& v_{q}=R \quad i_{q}+L \frac{d i_{q}}{d t}+\omega_{e} L i_{d}+v_{q 1} \\
& v_{d}=R \quad i_{d}+L \frac{d i_{d}}{d t}-\omega_{e} L i_{q}+v_{d 1}
\end{aligned}
$$

Applying the Laplace transforms to the above two equations,

$$
\begin{aligned}
& v_{q}=(R+s L) i_{q}+\omega_{e} L i_{d}+v_{q 1} \\
& v_{d}=(R+s L) i_{d}-\omega_{e} L i_{q}+v_{d 1}
\end{aligned}
$$

Considering,

$$
\begin{aligned}
& v_{q}^{\prime}=(R+s L) i_{q} \\
& v_{d}^{\prime}=(R+s L) i_{d}
\end{aligned}
$$


In order to design the current control loops the following equations can be used [4]:

$$
F(s)=\frac{i_{q}}{v_{q}^{\prime}}=\frac{i_{d}}{v_{d}^{\prime}}=\frac{1}{R+s L}
$$

Substituting (10), (11) in (8), (9) respectively, and being $v_{\mathrm{q}}(\mathrm{s})=0$ the reference for the voltages values $v_{\mathrm{q} \_ \text {ref }}$ and $v_{\mathrm{d}_{-} \text {ref }}$ can be obtained by:

$$
\begin{aligned}
& v_{q_{-} r e f}=-v_{q}^{\prime}-\omega_{e} L i_{d}+v_{q} \\
& v_{d_{-} r e f}=-v_{d}^{\prime}+\omega_{e} L i_{q}+v_{d}
\end{aligned}
$$

The values of $v_{\mathrm{q}}$ ref and $v_{\mathrm{d} \_ \text {ref }}$ are considered to be the reference input values to the PWM converter by which level of DC voltage and required power factor is achieved. In the similar way, the control design of the RSC can be obtained as the same way considered for the GSC.

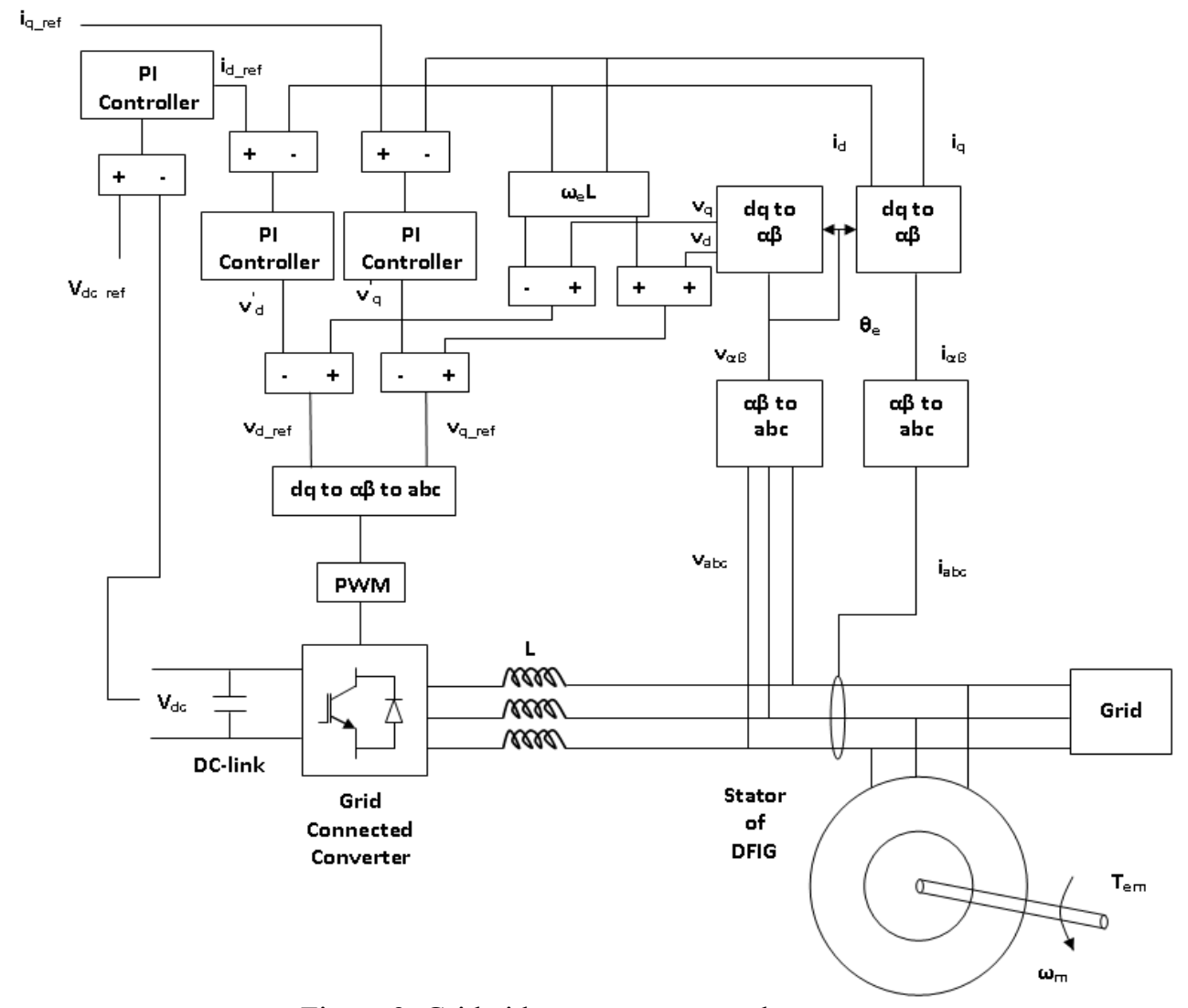

Figure 2. Grid-side converter control strategy

\subsection{Rotor-Side Converter Control}

The synchronous rotating reference dq frame is used in the RSC control of DFIG with the d-axis aligned with the stator flux position. The typical configuration of the RSC control strategy is shown in Figure 3. By setting up the reference frame, decoupling between the electromagnetic torque and rotor the magnetizing current is obtained. By the calculated values of the rotor and the stator currents, the stator voltage and the rotor position, the control of the PWM converter fed to the generator rotor is obtained.

As shown in Figure 3, the PI controllers are employed for the control of the RSC of the DFIG, likewise, in place of PI controllers the ANN and the Hybrid controllers are employed and the results are described. The dq referential rotor voltage can be obtained from (15) and (16). 


$$
\begin{aligned}
& v_{d}^{\prime r}=R_{r} i_{d}^{r}+\sigma L_{r} \frac{d i_{d}^{\prime r}}{d t} \\
& v_{q}^{\prime r}=R_{r} i_{q}^{r}+\sigma L_{r} \frac{d i_{q}^{\prime r}}{d t}
\end{aligned}
$$

As shown in Figure 3, the voltages $v_{\mathrm{d}}^{\mathrm{r}}$ and $v_{\mathrm{q}}^{\mathrm{r}}$ respectively are obtained by applying the error signals $\mathrm{i}_{\mathrm{d}}^{\mathrm{r}}$ and $\mathrm{i}_{\mathrm{q}}^{\mathrm{r}}$ to the PI controller. To obtain the reference voltages $v_{\mathrm{d}_{-} \text {ref }}^{\mathrm{r}}$ and $v_{\mathrm{q} \_ \text {ref }}^{\mathrm{r}}$, [4], the decoupling terms are added to (15), (16) respectively in order to compensate the control, the equations in accordance are given by

$$
\begin{aligned}
& v_{d_{-} r e f}^{r}=v_{d}^{\prime}-\sigma L_{r} i_{q}^{r} \omega_{\text {slip }} \\
& v_{q_{-} \text {ref }}^{r}=v_{q}^{\prime r}+\left(L_{m} i_{m s}+\sigma L_{r} i_{d}^{r}\right) \omega_{\text {slip }}
\end{aligned}
$$

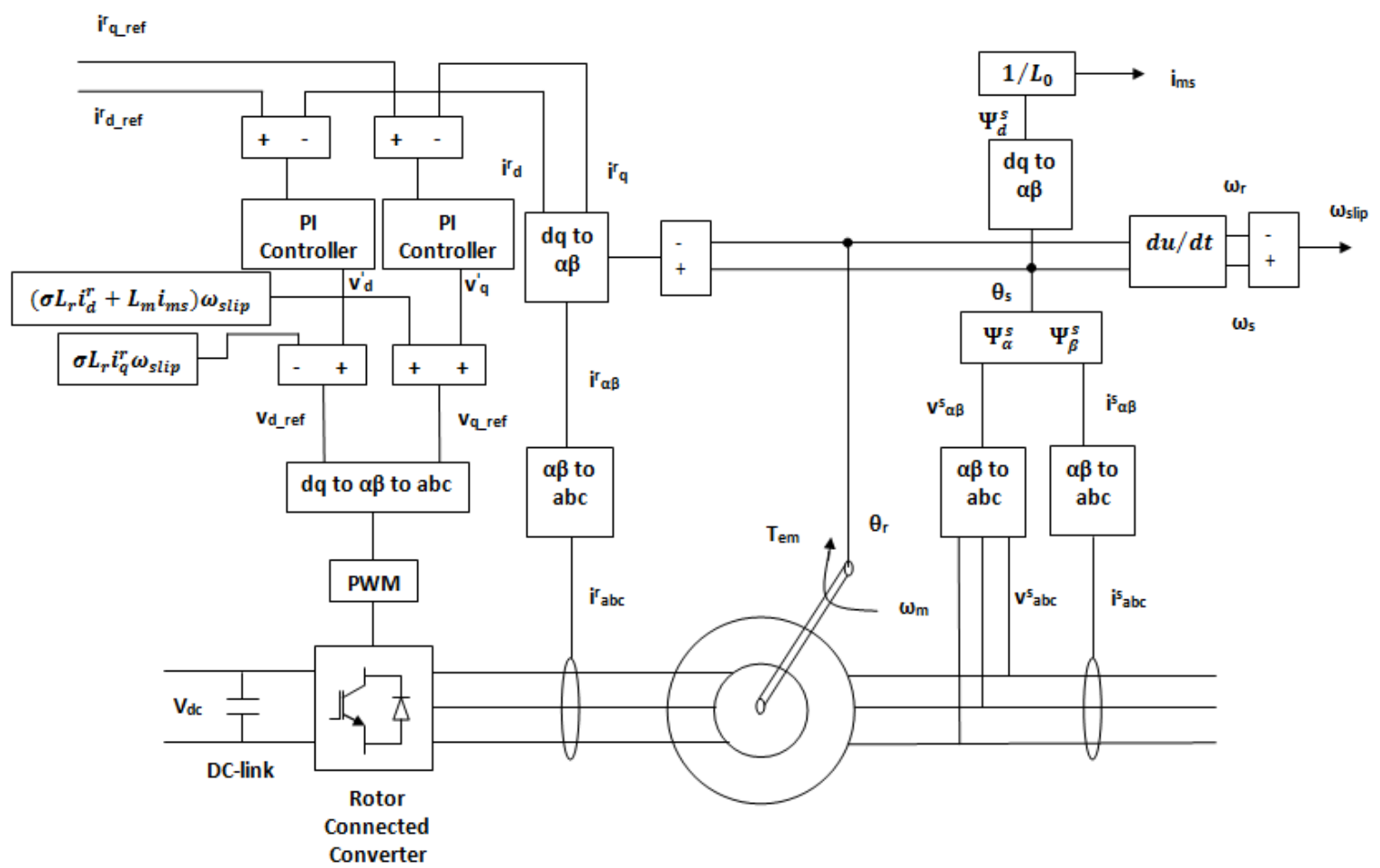

Figure 3. Rotor-side converter control strategy

\section{HYBRID AND ANN CONTROLLER BASED DFIG}

The new control system will use a Hybrid and NN to substitute some blocks of the traditional system of vector control, [14].

Thus, it is intended to present a control system based on hybrid neural networks to be used in the control system alternatively to the one based on PI controllers, with the intention of efficiently extract the wind energy, i.e. to be able to extract the maximum power of the turbine during some situations of functioning through the estimation of the control parameters for the grid-side and rotor-side converters.

\subsection{Architecture of Neural Network (NN) Controller}

In MATLab/Simulink Neural Network Toolbox software can be used in four different ways viz., Graphical User Interfaces (GUIs), basic command line operations, customization and the ability to modify any of the functions contained in the toolbox, GUIs is used for neural network training in this paper. The tasks like function fitting, pattern recognition, data clustering and time series analysis can be quickly and easily accessed with GUIs; of these tasks mentioned the neural network function fitting tool is accessed by GUI to define the NNs in this paper. In the function fitting the standard NN that is used is a two-layer feed 
forward network, with a sigmoid transfer function in the hidden layer and a linear transfer function in the output layer. For all the NNs which are replaced in place of PI controllers in all the three cases described in the paper, the NNs are trained by the data set which is taken from each individual input and output of a PI controller.

The learning algorithm updates the values of the weights and bias values according to the Levenberg-Marquardt Back Propagation (BP) algorithm with sigmoid hidden neurons and linear output neurons as the activation functions used in each layer. The input-target vectors will be randomly divided into three sets. The first set of $70 \%$ will be used for training the patterns, second set of $15 \%$ will be used to validate that the NN is generalizing and to stop training before over fitting and the third set of $15 \%$ will be used as a completely independent test of $\mathrm{NN}$ generalization. For all the NNs the training is continued until the validation checks are reached to six iterations i.e, the validation error failed to decrease for six iterations. After performing all the training steps the NN which is created is used for the replacement of corresponding PI controller and similar procedure is adopted to obtain other NNs.

For the rotor-side controller was used a 1-40-1 neural network configuration, where the inputs are the stator and rotor currents, the rotor-side reference currents and the rotor angular speed, and the outputs are the reference voltages to control the rotor-side converter.

For the grid-side controller was used a 1-40-1 neural network configuration, where the inputs are the stator voltages and currents, the grid-side reference currents, and the angular frequency $\omega \mathrm{s}$, and the outputs are the reference voltages to control the grid-side converter.

\section{RESULTS AND DISCUSSION}

\subsection{Reactive Power Control}

The proposed control strategies have been implemented using MATLab/Simulink and results are presented. In this section, the performances of the controllers are analyzed for the variation of reactive power. The reactive power is varied with step change in value from $-0.16 \mathrm{p}$.u. to $-0.04 \mathrm{p}$.u applied at $0.03 \mathrm{secs}$ up to 0.13 secs as shown in Figure 6(b). The GSC and RSC's reference direct and quadrature axis voltages for the PI (red in color), NN (green in color), and Hybrid (blue in color) controllers, which are generated by the current regulators are shown in Figure 4(a), (b) and 5(a), (b) respectively. The figures shows clearly that the performances of all the controllers are almost identical for the $\mathrm{v}_{\mathrm{ds}}$ and when compared with $\mathrm{v}_{\mathrm{qs}}, \mathrm{v}_{\mathrm{dr}}$, and $\mathrm{v}_{\mathrm{qr}}$, the response of the hybrid controller has less amplitude of the transients while during the starting of the performance and even when there is any step change and also it is more desirable as it has faster response in reaching the steady-state value after 0.13 secs.

The component of the quadrature axis is generally used to regulate the reactive power, here from the figures 4(b) and 6(b), it is clearly indicated that the quadrature component of the reference stator voltage significantly controls the reactive power of DFIG. The component $\mathrm{v}_{\mathrm{qs}}$ has lesser overshoot and reaches stability quickly compared to ANN and PI controllers during the step change in reactive power, which can be clearly observed in Figure 4(b).

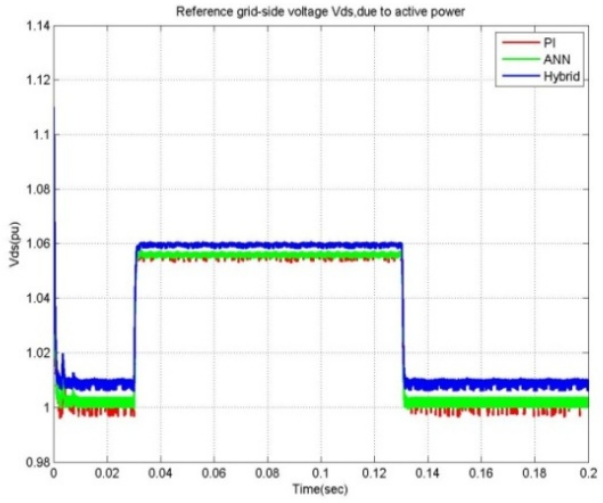

(a)

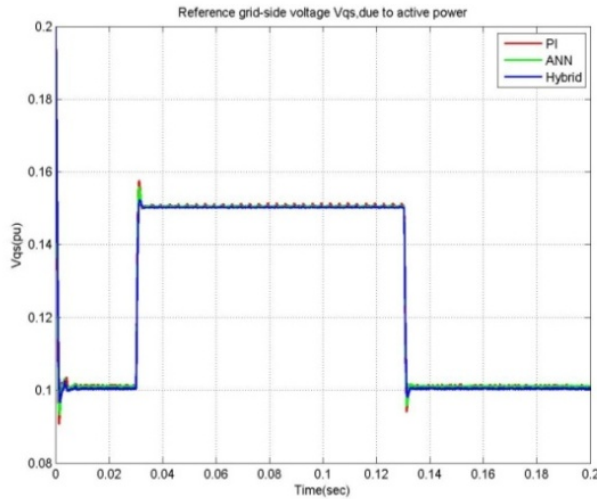

(b)

Figure 4. (a) Reference grid-side voltage $v_{\mathrm{ds}}$, due to reactive power control for PI control and NN control; (b) Reference grid-side voltage $v_{\mathrm{qs}}$, due to reactive power control for PI control, NN control and Hybrid control. 
Similarly, the component of the reference rotor-side voltage vdq has lesser overshoot, lesser oscillations and quickly reaches the stable value for hybrid controller as shown in Figure 5(a), (b). The component $\mathrm{v}_{\mathrm{dr}}$ is almost zero and the component $\mathrm{v}_{\mathrm{qr}}$ is almost analogous to the active power $\mathrm{P}$. The responses of the active and reactive powers delivered to the grid for the case of reactive power control are shown in Figure 6(a), (b). The responses clearly show that the hybrid controller is more advantageous as it exhibits better performance in reaching the stable operation with low transients and low peak overshoot.

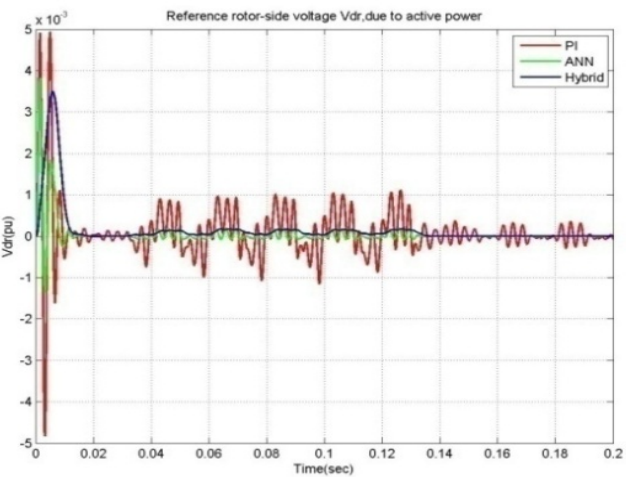

(a)

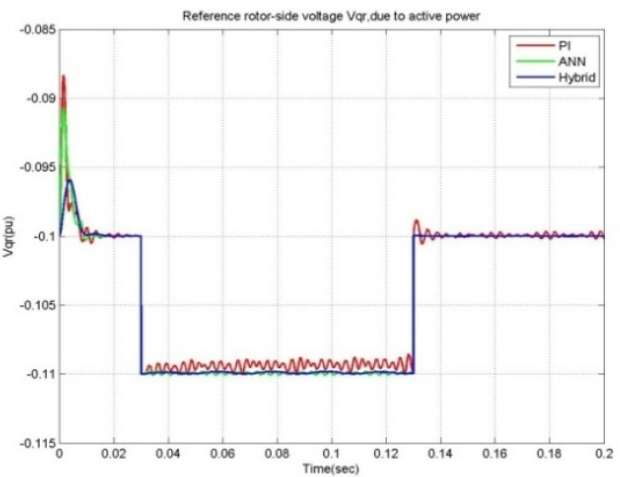

(b)

Figure 5. (a) Reference rotor-side voltage $v_{\mathrm{dr}}$, due to reactive power control for PI control and NN control; (b) Reference rotor-side voltage $v_{\mathrm{qr}}$, due to reactive power control for PI control, NN control and Hybrid control.

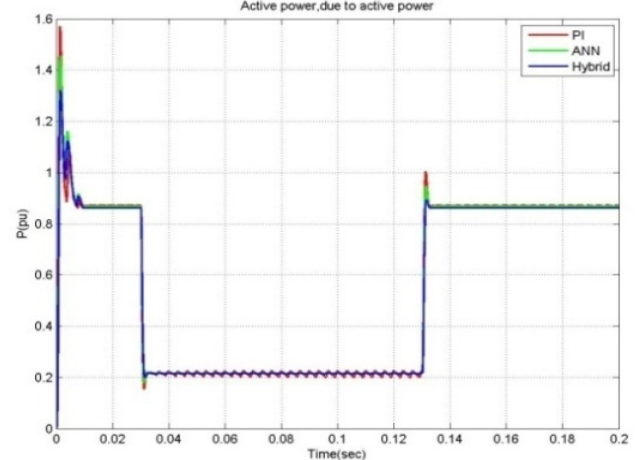

(a)

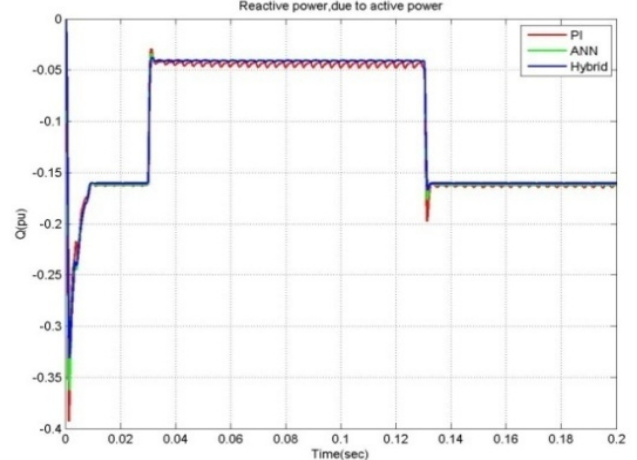

(b)

Figure 6. (a) Active power, due to reactive power control for PI control and NN control; (b) Reactive power, due to reactive power control for PI control, NN control and Hybrid control.

\subsection{Active Power Control}

In the case of active power control, the variation of the active power is obtained by the variation of the quadrature component of the rotor current $\mathrm{v}_{\mathrm{qr}}$ as ahown in Figure 8(b). Due to the variation of $\mathrm{v}_{\mathrm{qr}}$, it results in a step change from 0.8 p.u to 0.2 p.u. in the active power as shown in Figure 9(a). Figure 7(a) shows the GSC reference direct axis component of stator voltage for the controller, which clearly shows the step change of value because of the step change in active power. The performances of the controllers are almost identical for $\mathrm{v}_{\mathrm{ds}}$. Figure 7(b) shows the GSC reference quadrature axis component of stator voltage for the controller, which shows that the sudden change of the value of $\mathrm{v}_{\mathrm{qs}}$ at exactly $0.03 \mathrm{secs}$ and $0.13 \mathrm{secs}$ where the step change is applied and it, implicates the reactive power Q, which is almost zero value. Here the performances of $\mathrm{NN}$ and hybrid controllers are identical and the peak values are less compared to PI controller. Figure 8(a), (b) shows the RSC reference direct and quadrature axis components of rotor voltage for the controllers. The ripples at the starting and during the step change are quite less for hybrid controller compared to $\mathrm{NN}$ and PI controllers. 
The active and reactive powers results due to change in active power control is shown in Figure 9(a), (b). The performance of the proposed controller is quite comparable with the performance of ANN and it is far better in comparison with PI controller as it has lesser amplitude transients and reaches the steadystate condition quickly. The maximum difference between these control types is less than $0.5 \%$, which can be clearly observed from the Figure 9(a), (b).

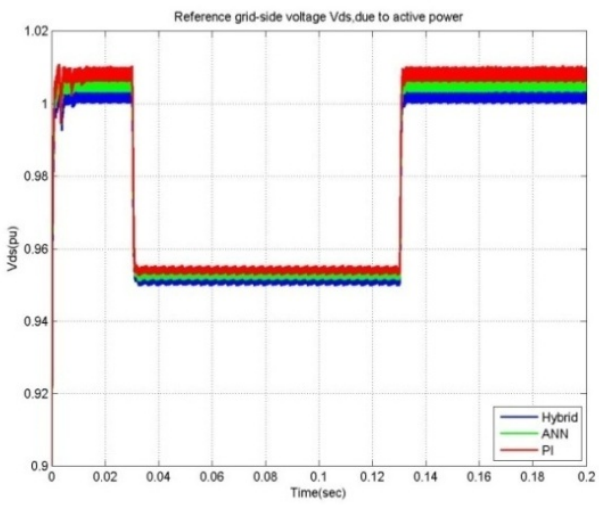

(a)

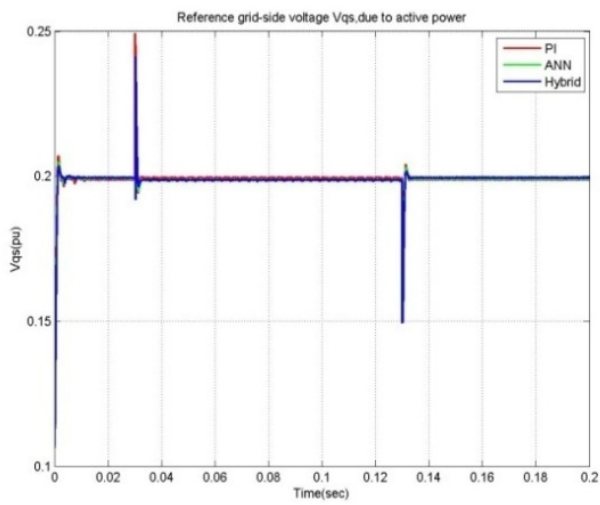

(b)

Figure 7. (a) Reference grid-side voltage $v_{\mathrm{ds}}$, due to active power control for PI control and NN control; (b) Reference grid-side voltage $v_{\mathrm{qs}}$, due to active power control for PI control, NN control and Hybrid control.

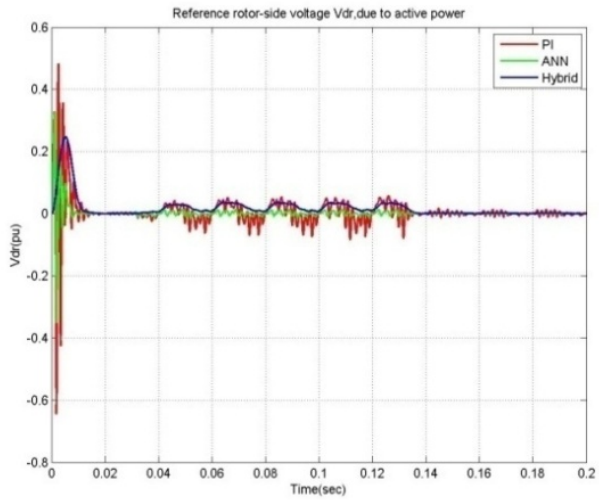

(a)

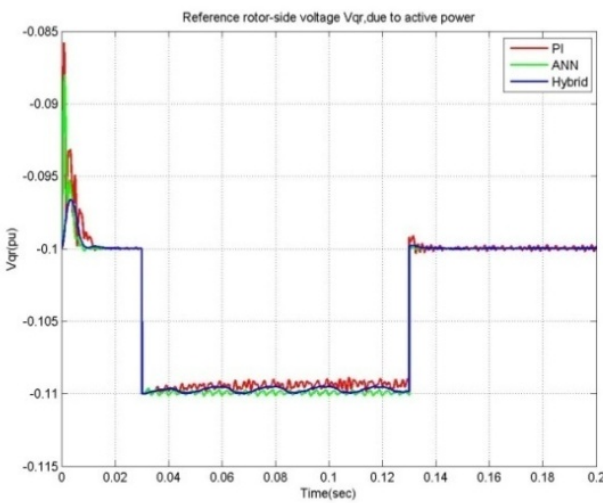

(b)

Figure 8. (a) Reference rotor-side voltage $v_{\mathrm{dr}}$, due to active power control for PI control and NN control; (b) Reference rotor-side voltage $v_{\mathrm{qr}}$, due to active power control for PI control, NN control and Hybrid control.

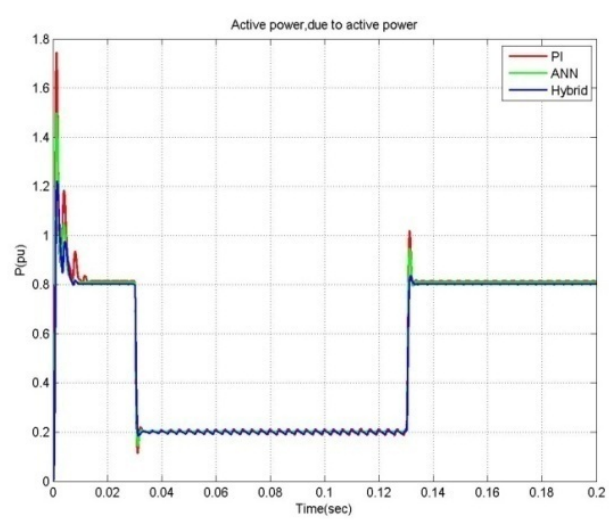

(a)

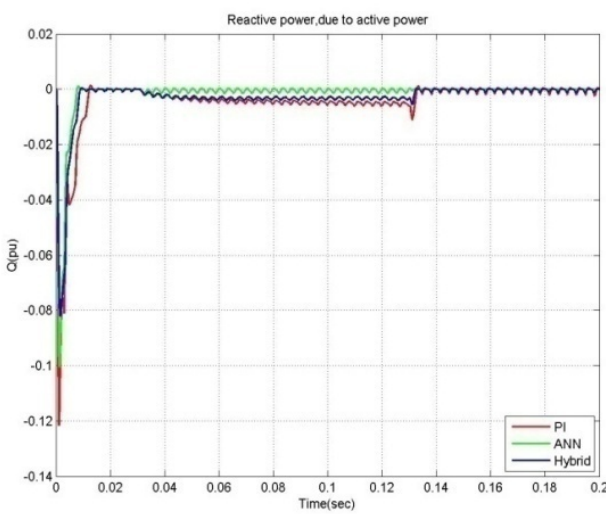

(b)

Figure 9. (a) Active power, due to active power control for PI control and NN control; (b) Reactive power, due to active power control for PI control, NN control and Hybrid control. 


\subsection{Phase-to-Earth Fault}

In this section, the response of the DFIG is analyzed for a phase-to-earth fault on the line of electrical network near to the DFIG. The fault is considered to be occurred at $t=0.02 \mathrm{~s}$ for a duration of $3 \mathrm{~ms}$.

Similar to the previous sections, Figures 10(a), (b) and 11(a), (b) shows the reference direct and quadrature voltage signals for the control the GSC and RSCs, respectively. The response of $\mathrm{v}_{\mathrm{ds}}$ as shown in Figure 10(a), clearly indicating the application of fault condition at $t=0.02 \mathrm{~s}$, the result is identical for all the described controllers, however the hybrid controller produces low overshoot during the transient condition. The response of $\mathrm{v}_{\mathrm{qs}}$ is almost similar for all the controllers, still the hybrid controller exhibits lesser transient amplitude compared to other two controllers. In both the Figures 10(a), (b), it can be clearly observed that there is a sudden increase of value of $\mathrm{v}_{\mathrm{ds}}$ and sudden decrease of value of $\mathrm{v}_{\mathrm{qs}}$, indicating that the overall value of the reference stator-side voltage is falls due to the sudden application of fault condition. As illustrated in Figures 11(a), (b), the components of $\mathrm{v}_{\mathrm{dr}}$ and $\mathrm{v}_{\mathrm{qr}}$ are almost zero indicating that high amounts of currents pass through the rotor winding during the abnormal condition, which is similar cause in stator winding also. The responses shows the performances of the hybrid and ANN are identical and better in the transients when compared to PI controller.

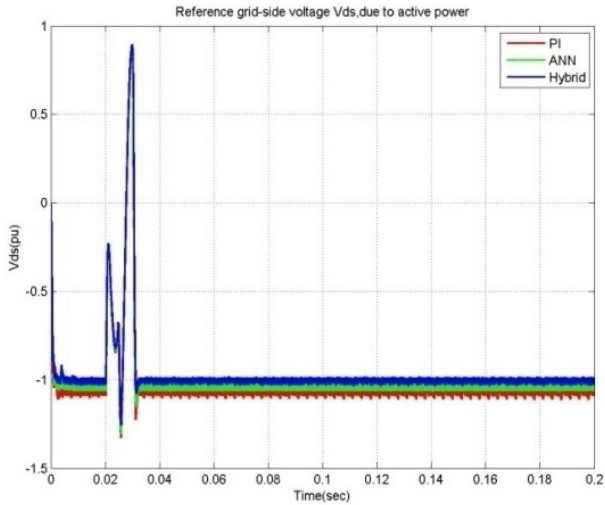

(a)

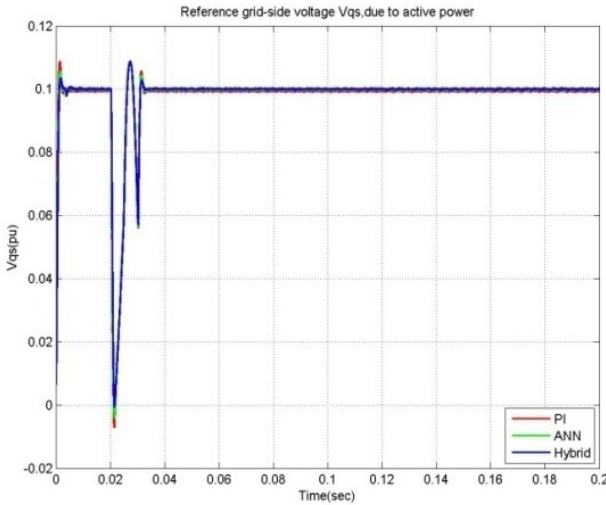

(b)

Figure 10. (a) Reference grid-side voltage $v_{\mathrm{ds}}$, due to a phase-to-earth fault for PI control and NN control; (b) Reference grid-side voltage $v_{\mathrm{qs}}$, due to a phase-to-earth fault for PI control, NN control and Hybrid control.

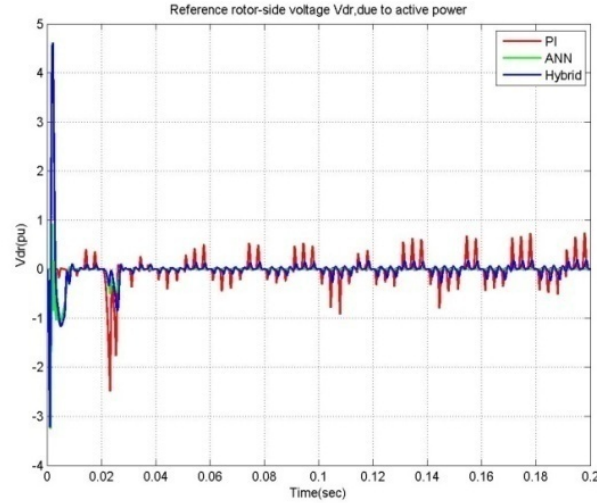

(a)

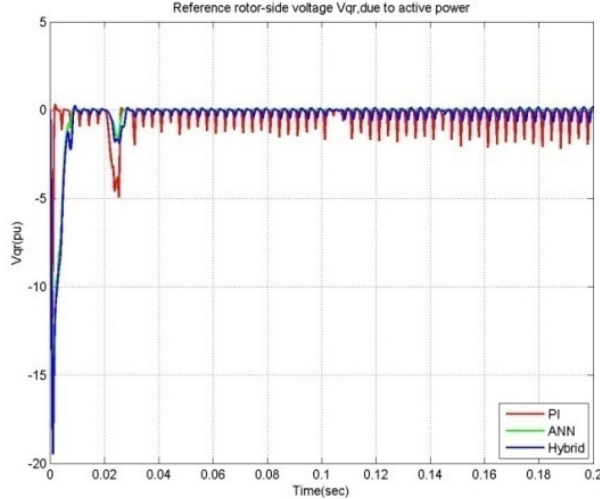

(b)

Figure 11. (a) Reference rotor-side voltage $v_{\mathrm{dr}}$, due to a phase-to-earth fault for PI control and NN control; (b) Reference rotor-side voltage $v_{\mathrm{qr}}$, due to a phase-to-earth fault for PI control, NN control and Hybrid control.

The responses of the active and reactive powers for the phase to earth fault condition are shown in Figures 12(a), (b). From the figure it is clearly verified that transients or the disturbances which are caused in $\mathrm{P}$ and $\mathrm{Q}$ delivered to the grid are quite smoother for the case of hybrid controller when compared to $\mathrm{NN}$ and 
PI controllers and the peaks developed with NN and PI controllers are more than $2.4 \mathrm{p} . \mathrm{u}$., in the response of active power, which may affect the electronic devices used in the GSC and RSCs. With the hybrid controller the steady state condition is reached quickly compared to NN and PI controllers, it can be clearly understood from the Figures 12(a), (b), that the performance of the proposed controller is quite comparable with the performance of ANN and PI controller.

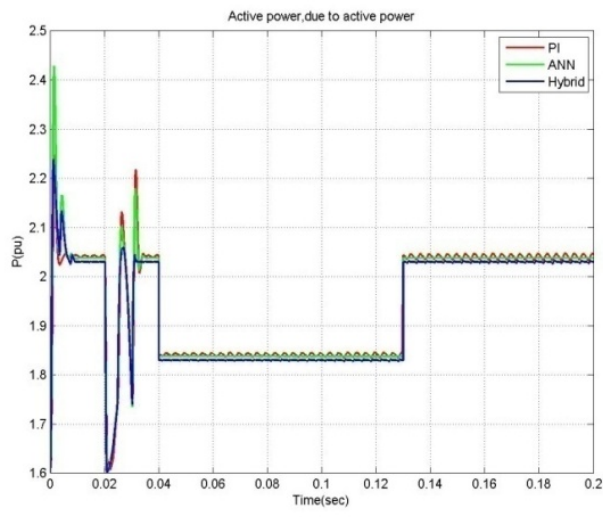

(a)

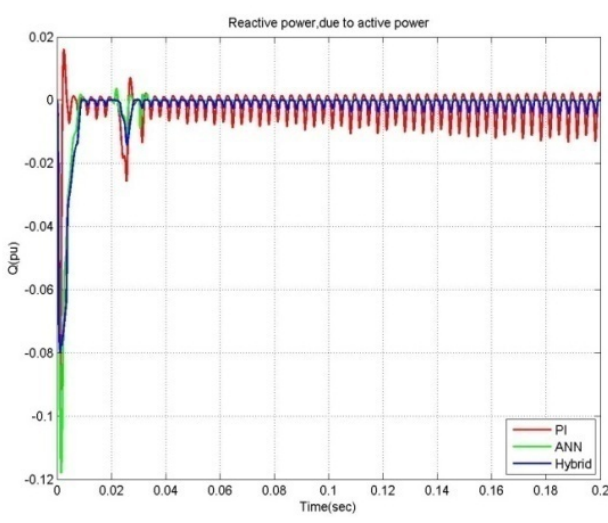

(b)

Figure 12. (a), (b) Active power, due to a phase-to-earth fault for PI control and NN control; (c), (d) Reactive power, due to a phase-to-earth fault for PI control, NN control and Hybrid control.

\section{CONCLUSION}

There are certain advantages of using Hybrid controllers when comparing with artificial neural network control and PI control of DFIG. There are smaller overshoots, or absence of them in some cases, which gives a faster response, i.e. the system retakes the permanent regimen in lesser time; and smaller oscillatory behavior. The Hybrid ANN-based system that estimates the control parameters of the generator showed satisfactory characteristics as was verified in the presented results. It was demonstrated that the reference signals for the grid-side and rotor-side converters of the DFIG can be obtained using control systems based on ANNs. These can show the superiority of the proposed Hybrid control of DFIG with the referred advantages.

\section{REFERENCES}

[1] J. F. Walker, N. Jenkins, “Wind Energy Technology”, John Wiley \& Sons, Ltd, 1997.

[2] T. Ackermann, "Wind Power in Power Systems", John Wiley \& Sons, Ltd, England, 2005.

[3] C. Ong, "Dynamic Simulation of Electric Machinery”, Prentice Hall, 1998.

[4] R. Pena, J. C. Clare, G. M. Asher, "Doubly fed induction generator using back-to-back PWM converters and its application to variable-speed wind-energy generation", IEE Proc.-Elect. Power Appl., vol. 143, no 3, May 1996.

[5] A. Tapia, G. Tapia, J. X. Ostolaza, J. R. Saenz, R. Criado, J. L. Berasategui, "Reactive power control of a wind farm made up with doubly fed induction generators", (I) and (II), IEEE PortoPower Tech Conference, 2001.

[6] J. L. Rodríguez-Amenedo, S. Arnalte, J. C. Burgos, "Automatic generation control of a wind farm with variable speed wind turbines", IEEE Transactions on Energy Conversion, vol. 17, no 2, pp. 279-284, 2002.

[7] Guofeng Yuan and et al, "Vector control and synchronization of doubly fed induction wind generator system" Power Electronics and Motion Control Conference, IPEMC 2004. The 4th International (Volume: 2), pp. 886 $890,2004$.

[8] Batlle, C. and et al "A Robustly Stable PI Controller For The Doubly-Fed Induction Machine" IEEE Industrial Electronics, IECON 2006 - 32nd Annual Conference, pp. 5113 - 5118, 2006.

[9] Dendouga, A. and et al "Power Flow Control of a Doubly Fed Induction Generator (DFIG)" International Journal of Electrical and Power Engineering, vol. 1, no. 2, pp. 132-137, 2007.

[10] Brekken, T.K.A. and et al "Control of a Doubly Fed Induction Wind Generator under Unbalanced Grid Voltage Conditions" Energy Conversion, IEEE Transactions on, vol. 22, no. 1, pp. 129 - 135, 2007.

[11] Erlich, I. and et al "Reactive power generation by DFIG based wind farms with AC grid connection" Power Electronics and Applications, European Conference on, pp. 1-10, 2007.

[12] Balduino Cezar, R. and et al "Reactive Power Control Design in Doubly Fed Induction Generators for Wind Turbines", IEEE Transactions on Industrial Electronics, vol. 56, no. 10, pp. 4154-4162, 2009. 
[13] Orlando Manuel Soares and et al "Analysis and NN-Based Control of Doubly Fed Induction Generator in Wind Power Generation" International Conference on Renewable Energies and Power Quality (ICREPQ'09) Valencia (Spain), 15th to 17th April, 2009.

[14] S. Haykin, “Neural Networks. A Comprehensive Foundation”, $2^{\text {nd }}$ Edition, Prentice Hall, 1999.

\section{BIOGRAPHIES OF AUTHORS}
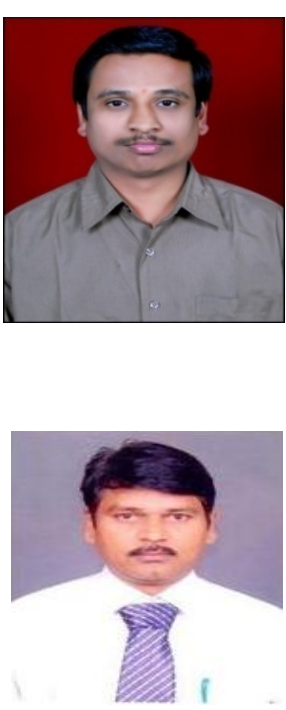

G. Venu Madhav received his B.Tech. degree in Electrical and Electronics Engineering from Jawaharlal Nehru Technological University, Hyderabad in 2002. M.Tech. degree in Power and Industrial Drives from Jawaharlal Nehru Technological University, Anantapur in 2005. He is pursuing Ph.D. from Jawaharlal Nehru Technological University, Hyderabad. Currently he is working as Associate Professor, Dept. of EEE, BVRIT, Narsapur, Medak Dist. He has published several National and International Journals and Conferences. His area of interest is Advanced Control strategies of Electric Drives, Microprocessors and Microcontrollers, Fuzzy logic \& ANN applications, and Network Analysis. Have professional society memberships in IETE (M), ISTE (LM), IE (AM), SESI (LM) and IAENG (M).

Dr. Y.P.Obulesu received his B.E. degree in Electrical and Electronics Engineering from Andhra University, Visakhapatnam in 1996. M.Tech. degree in Power Electronics and Drives from IIT, Kharagpur, in 1998. He received his Ph.D. degree from Jawaharlal Nehru Technological University, Hyderabad in 2006. Currently he is working as a Professor, Dept. of EEE, KL University, Vijayawada, Krishna Dist. He has published several National and International Journals and Conferences. His area of interest is Advanced Control strategies of Electric Drives, SMPS, Multilevel inverters, Harmonic minimization, power quality, FACTs, Solar powered Electric Vehicles, DSP \& FPGA control of power electronics and drives, Wavelets, Fuzzy logic \& ANN applications to power electronics and drives. Have professional society memberships in IEEE, ISTE (LM) and SSI (LM). 